\title{
The Relationship Between Academic Performance of Pupils Coming from Electrified and Non-Electrified Homes of Grade Seven Pupils from Mubanga Ndhlovu Primary School in Chibombo District
}

\author{
Patrick Mubanga $^{1^{*}} \quad$ Dr. Daniel Ndhlovu ${ }^{2}$ \\ 1.School of Education, University of Zambia and Open, Great East Road, P. O. Box 32379, Lusaka, Zambia \\ 2.School of Education, Department of Education Psychology, Sociology and Special Education, University of \\ Zambia, Great East \\ Road, P. O. Box 32379, Lusaka, Zambia
}

\begin{abstract}
Primary schools in rural areas do not offer appropriate facilities that enable pupils' to study at night. Therefore, an electrified home provides an environment for pupils to have an extended study time and access to facilities such as radio and television that may be a crucial academic resource for pupils. However, it has been observed that, so far there is no evidence that necessarily highlights that academic performance for pupils coming from electrified homes is better than those from non-electrified homes in the rural part of Chibombo district. In view of the above, a study was conducted to examine the relationship between academic performance of the two groups from Mubanga Ndhlovu Primary School in Chibombo District, Zambia. In establishing the aforementioned relationship, the study adopted a positivist paradigm such that the school was selected using simple random sampling from a population of five rural schools that were electrified in the rural part of Chibombo District from 2006 to 2012. Collected data was analyzed using a statistical analysis software tool called Stata (version 14), using Bivariate analysis, Pearson's Chi-square test and multivariate logistic regression. The results revealed that there was no difference in terms of academic performance between pupils coming from electrified and non-electrified homes. Not only did the study show the above relationship, but also revealed that there was no difference in the academic performance between male and female pupils, and this was supported by a statistically significant level of association between the number of family members living with the pupil at home and their academic performance. Further, the results also reflected that three factors are associated with the academic success of learners and these are listed as: the number of people living with the respondents, having a radio in both types of homes from which the pupils come, and thirdly, the factor concerned with guardians' level of education which only affects pupils coming from electrified homes, though this factor can only be analyzed up to a certain degree. According to the results, it is observed that academic performance is affected by a number of variables which is in line with the theory of Educational Productivity that guided the study. The theory merely highlights that academic performance is influenced by various factors.It is, therefore, concluded that there is no statistically significant difference between pupils coming from electrified and nonelectrified homes and there is also no difference in the academic performance between boys and girls. A conclusion may be made that that three factors are associated with academic success of learners, which have been mentioned in the paragraph. In this vain, it is recommended that more houses should be electrified so that pupils are encouraged to listen to educational programs on the radio. It is also recommended that parents or guardians from electrified homes should aspire to acquire higher qualifications such as University degree as this will persuade pupils to follow suit and excel academically.
\end{abstract}

Keywords: electrified, academic performance, relationship, environment, educational productivity

DOI: $10.7176 / \mathrm{JEP} / 11-4-06$

Publication date: February $29^{\text {th }} 2020$

\section{Introduction}

The variables that affect the academic performance of pupils are inside and outside school and may be termed as student factors, family factors, school factors and peer factors (Crosnoe, Johnson \& Elder, 2004). Bearing in mind the variables affecting the academic performance of pupils, the study assumed the school factors to be constant while the pupils' and home factors were explored. This assumption was made considering that the role of electricity in rural communities facilitates extension of study time for the pupils. This extension is normally practical at a home that is electrified taking into consideration that primary schools do not offer facilities to enable pupils' study at night. The home atmosphere may therefore provide an environment for pupils to have an extended study time and could also provide facilities such as radio and Television (TV) that could enhance pupils' academic performance.

Thus, in order to determine the relationship between academic performance of pupils coming from electrified and non-electrified homes, a comparison was made in terms of academic performance of pupils 
coming from homes with and without electricity. The study also attempted to identify factors affecting academic performance of pupils coming from electrified rural homes. A questionnaire was administered to 229 pupils coming from electrified and non-electrified homes. Using simple random sampling, grade seven pupils were selected as respondents.

In this study academic performance was synonymous with performance during mock exams. Further, an electrified home meant a home with power from either ZESCO Limited or Solar Home Systems. A nonelectrified home is one without lighting derived from ZESCO or Solar homes Systems but could use batteries to power gadgets such as radio or TV.

\section{Statement of the problem}

The purpose of electrifying rural homes is to support socioeconomic development in the rural areas which translates to improved living conditions of the community. However, it has been observed that, there is really no evidence provided to show that electrification of a home, which is one of the socioeconomic factors, helps to improve academic performance of pupils. This is a problem considering that Government is channeling a lot of resources towards electrifying rural homes with the aim of improving socioeconomic development.

\section{Purpose of the study}

The research sought to investigate the relationship between academic performance of pupils coming from both electrified and non-electrified homes.

\section{Objectives of the study}

The research had the following objectives;

a. To examine the relationship between academic performance of pupils coming from electrified and nonelectrified homes

b. To identify factors affecting academic performance of pupils coming from electrified homes

\section{Research Questions}

The following were the research questions;

a. What is the relationship between academic performance of pupils coming from electrified and nonelectrified homes?

b. What are the factors affecting academic performance of pupils coming from electrified homes?

\section{Significance of the study}

This research was conducted with the hope that the results of the study aid in providing guidance in a manner that gives:

a. Insight to policy makers in the education and energy sectors to help in the formulation of appropriate policies aimed at scaling-up the significance of electrifying a home and the relationship with academic performance of pupils

b. Bring awareness to parents and teachers on the benefits of an electrified home to pupils' academic performance.

\section{Study site}

The study site under consideration was Mubanga Ndhlovu primary school located in Chibombo District, Zambia.

\section{Theoretical perspective}

\subsection{Theory of Educational Productivity}

The study was guided by the theory of Educational Productivity (ED) by Walberg et al., (1981) which identified three groups of nine factors that include aptitude covering ability, development and motivation: instruction covering amount and quality: environment which covers home and classroom, school environment, peers and television (Roberts, 2007). The theory highlights the optimization of each of these nine identified factors in order to bring about academic performance and how these factors interact with each other in maximizing academic performance.

\section{Research Methodology}

The philosophical assumption that the study adopted was positivist paradigm considering the fact that statistical measurements and quantifiable elements were adopted in conducting the study. This meant that the study was objective, and the researcher was independent of the study.

Also, a descriptive research design and a structure questionnaire was administered to respondents. The study used descriptive, bivariate and logistic regression to analyse the data that was collected in order to 
establish the relationship.

The target population for the research study was Chibombo District where five (5) schools were electrified during the period 2006 to 2012. Using simple random sampling, Mubanga Ndhlovu Primary School was selected from the five schools that were electrified during the period. Additionally, using simple random sampling, grade seven pupils were selected as respondents for the study. This entailed that all grade seven pupils got an opportunity to complete the questionnaire where a total of 229 respondents were selected.

The instrument used in gathering and collecting data was a structured questionnaire. Data was collected by administering the questionnaires, which mostly contained closed questions to the selected respondents. Closed questions were preferred because they permit collection of data in a standardized way on variables that are quantifiable. Before embarking on the actual study, a pilot study was undertaken in order to test the instrument and also to plan for potential misunderstandings or biasing effects of different questions in the questionnaire.

Collected data was checked for consistency, uniformity and accuracy, coded and then entered into Microsoft Excel 2016 which was used to create a data entry screen because of its capabilities to capture quantitative information. The entered data was then exported to Stata version 14 for analysis. Using Bivariate analysis, Pearson's Chi-square test and multivariate logistic regression, data was analyzed.

\subsection{Reliability and Validity}

Reliability was achieved by repeating certain questions within the questionnaire to ensure that pupils were consistent in the way they were responding to the questions. Using Face Validity, the research instrument was reviewed by the experts such as the supervisor and the teachers to confirm that the instrument was measuring what it was intended to measure. According to Amin (2005), validity is determined by the expert's judgment.

\section{Findings}

The findings of the research are grouped under the themes: Background information, Bivariate Analysis and Multivariate Logistic Regression Analysis which are narrated as follows:

\subsection{Background information (refer to Appendix 1 -table 1)}

Regarding the background information for the respondents, the results show that most of the male pupils 77 $(66.4 \%)$ are aged between 10 and 14 years compared to $88(80 \%)$ of the female pupils in the same age group. The results further show that 39(33.9 \%) of the male pupils were aged between 15-19 years compared to only $22(20 \%)$ of the female pupils.

Pupils who lived with their mother and father were $76(65.5 \%)$ and $66(60 \%)$ for male and female pupils respectively. Furthermore, about 25 (22\%) of the female respondents reported that they live with a guardian who is not their mother or father compared to $13(11.2 \%)$ of the males who reported otherwise. Additionally, $22(19 \%)$ of the male respondents reported living only with their mothers compared to $17(15.5 \%)$ of the females who are living with their mothers. On one hand, only 5(4.3\%) of the male respondents reported living with their father while on the other, $2(1.8 \%)$ of the female respondents reported in this light.

The results disclosed that 31 (27 percent) of the male pupils had guardians with primary and secondary level education compared to 19 (17.3 percent and 29 (26.4 percent) of the female pupils who had guardians with primary and secondary education level respectively. The results further show that $26(22.6$ percent) of the male pupils had guardians who attained College education compared to 17(15.5 percent) of the females in the same respect. The results go on to show that $22(20$ percent) of the female pupils had guardians with university education compared to only $6(5.2$ percent $)$ of the male pupils in the same respect.

Regarding guardian's employment status, the results reveal that most of the respondents only have one of their guardians working (52.6 and 57.3 percent for males and female pupils respectively). Furthermore, the results show that 31.8 percent of the female pupils had both parents and guardian working compared to 30.2 percent of the male pupils in the same respect.

In terms of school attendance, most of the respondents attend school more than three (3) times 87.1 and 91.8 per cent for male and female pupils respectively). Also, the results show that about 6.9 percent of the male pupils attended school less than three (3) times compared to 3.6 percent of female's pupils in the same respect. More male pupils ( 6 percent) attend school three (3) times compared to 4.5 percent of female pupils in the same respect.

In considering the number of family members living with the pupils, the results highlight that the largest proportion of the pupils live in a family of 5-9 people (79.3 and 75.5 per cent of male and female pupils respectively). The results also show that about 12.7 percent of female pupils live in homes of $0-4$ people compared to 10.3 percent of male pupils in the same respect. The results further highlight that more female pupils (11.8 percent) compared to male pupils ( 8.6 percent) live in homes of $10-14$ people. Only 1.7 percent of the male pupils reported living in a home with more than 15 people.

Most pupils lived in homes that are electrified with 56.9 and 59.1 percent of the male and female pupils 
respectively. In addition, it can be noted from the results that 43.1 percent of male pupils lived in homes that had no electricity compared to 40.9 percent of female pupils in the same respect.

The results show that 81 percent and 82.7 percent of the male and female pupils reported to be studying at night respectively. On the other hand, the results show that 19 percent of the male pupils do not study at night compared to 17.3 percent of the female pupils in the same respect.

Regarding the duration pupils' study at home, the results show that 72.4 percent and 59.1 percent of the male and female pupils reported to study less than an hour respectively. On the other hand, the results show that only 27.6 percent of the male pupils studied for more than one hour compared to 40.9 percent of the female pupils in the same respect.

In terms of whether having electricity at home encouraged the pupils to study at night, the results show that 64.7 percent and 74.5 percent of the male and female pupils reported that electricity at home does encourage them to study at night respectively. On the other hand, the results show that about 35.3 percent of the male pupils reported not to be encouraged to have night studies even when they have electricity at home compared to 25.5 percent of the female pupils in the same respect.

The results show that 64.7 percent of the male come from homes with TV compared to 82 percent of the girls in the same respect. On the other hand, the results show that about 35.3 percent of the male pupils came from homes with homes without TV while 25.5 percent of the female pupils also came from homes without TV.

The results show that 73.3 percent of the male come from homes with Radio while 67.3 percent of the girls came from homes with Radio. On the other hand, the results show that about 26.7 percent of the male pupils came from homes without Radio while 32.7 percent of the female pupils also came from homes without Radio.

\subsection{Bivariate Analysis of Academic Performance and the control variables (Appendix 2 -table 2)}

The finding under Bivariate analysis of academic performance of pupils coming from electrified and nonelectrified homes is provided as follows:

According to the research, the results found that, the association between the main variables of interest (academic performance) and sex is not statistically significant at 95 percent confidence level. Despite this, the proportions indicate that a higher number of female pupils (49.1 percent) passed the examinations compared to male pupils (38.8 percent).

Further the results show that the association between academic performance and age is not significant. On the other hand, the proportions indicate that more pupils aged between 10 and 14 years (46.7 percent) than pupils aged between 15 and 19 years (36.1 percent) passed the examinations.

Additionally, the results reflect that who the child lives with is not associated with his or her academic performance. Although the results show that most pupils who passed the exams are those living with both mother and father compared to others. The results show that there is no statistically significant difference in academic performance of pupils who have working parents or not.

The results show that school attendance is not associated with pupils' academic performance. Although the results show that most pupils who passed the exams are those who have school attendance of more than three (3) times.

The results revealed that there is a significant association between the number of people living in the house and academic performance with $\mathrm{P}=01$ at $95 \%$ confidence level.

The results revealed that there is no significant association between pupils from electrified and nonelectrified homes with $\mathrm{P}>0.05$. The results therefore reveal that there is no difference in terms of academic performance between the two groups.

The results indicate that studying at night by pupils does not seem to be associated with academic performance at all levels of significance. On the contrary, the proportions also show that most (84.8 percent) of the pupils who reported that they study at night passed their exams compared to those pupils who do not study at night (79.5 percent). Despite this observation, the difference is still not statistically significant meaning the observed difference maybe as a result of chance or due to interactions with other variables rather than the variables of interest.

Regarding the association between the duration pupils' study at home and academic performance, the results do not show a significant association between the two variables. However, they do indicate that pupils (29.3 percent) who study less than an hour passed their exams compared to those pupils who study for more than an hour (37.8 per cent).

Regarding the association between electricity motivating pupils to study at night and academic performance, the results indicate that there is no statistically significant association between the two variables. The results further show that 68.7 percent of the respondents who reported that electricity at home encourages them to study at night passed their exams compared to 70.1 percent of respondents who reported that electricity at home does not encourage them to study at night, but they passed their exams.

In conclusion, we see that the research results indicate that the association between having a TV at home 
and positive academic performance shows no statistical significance, at 5 percent and 10 percent confidence level respectively. The results further show that 43 percent of the respondents who reported watching educational programs on TV passed their exams compared to 45 percent of respondents who reported not watching educational programs on TV. The results show statistically significant association at $90 \%$ confidence level between radio and academic performance. 40 percent of the respondents who reported listening to educational programs on Radio are revealed to have passed their exams compared to 54 percent of respondents who reported as not listening to educational programs on Radio.

\subsection{Multivariate Logistic Regression Analysis of Academic performance, electrification and other control variables (Appendix 3)}

Using multivariate logistic regression, various models were design such that factors were controlled for in the five models to identify factors affecting academic performance of pupils coming from electrified rural homes. The results were reported as Odds Ratios (OR), with a level of significance at $95 \%$. Thus, based on the results of the various models that is 1 up to 4 , the academic performance was not significantly related with pupils coming from electrified homes and did not also improve the association between academic performance and pupils coming from electrified homes. Further, with the introduction of various factors in the models, the value of OR between the association of the two variables was becoming smaller. However, in model 4, the results show that pupils who attend school less than three times $(\mathrm{OR}=0.228)$ or equal to three times $(\mathrm{OR}=0.324)$ have significantly lower odds respectively of passing compared to those who attend school more than three times.

In model 5, when factors related to home environmental factors mostly related to socioeconomic status of the pupil such as guardians level of education and employment, eating breakfast, number of people living with the respondents, having a TV and radio were included in the model, the value of OR increased from 0.882 to 0.946. Further, the variable measuring the number of people living with the respondents was significantly associated with academic performance, the results show that pupils from families with number of people between 5-9 have significantly higher odds $(\mathrm{OR}=4.071)$ of passing compared to those coming from families with less than 5 people or more than 9 .

Stemming from this research also, are results that the increase in OR, in terms of association between academic performance and learners coming from electrified homes is mainly attributed to two factors namely: the number of people living with the respondents and to a certain extent, pupils with guardians possessing university level of education ( $\mathrm{OR}=2.221)$. These factors have been identified as the key contributors to the rise in the OR considering that the value of OR for the remaining factors were approximately closer to 1 and their contribution was therefore insignificant. However, the result for pupil with guardians possessing university level of education was not statistically significant at $95 \%$ confidence level.

In view of the above, it can be observed that the odds of passing for a pupil coming from an electrified home increase when a pupil comes from a home with a number of people, that is, between 5-9. and to a certain extent, when the pupil has guardians possessing university level of education. Subsequently, the increase in OR reinforces the argument that to a certain degree socioeconomic factors especially the guardians' level of education to a certain extent contribute to high academic performance of learners coming from electrified homes.

\section{Discussion}

The descriptive analysis reveals that most of the respondents were males although the difference was not significant. In terms of age, most of the respondents were aged between 10 and 14 years, they lived with both their mother and father, had guardians who had reached primary and secondary education level and had only one of their guardians working. The results further revealed that there was no significant difference in terms of academic performance between male and female pupils even though proportionally, more female children $49 \%$ $(n=54)$ who lived in electrified homes performed better than males $39 \%(n=45)$ in the same respect.

In view of the above, the research finding is not consistent with previous studies which had highlighted that female pupils are less likely to perform better due to the increase in chores they have to do when they are at home. For this reason, female children are less likely to have enough time to study even when they live in electrified homes, because they are mostly tired. This finding is in line with the research study by UNICEF (2004) which revealed that household work such as carrying water, preparing food and washing clothes falls disproportionately to girls and women throughout the developing world. Therefore, it is the primary reason that girls find it difficult to study at night because they get tired.

Further, studies done by Jabor et al., (2011) revealed that gender plays a critical role in the student academic achievement. In a meta-analysis of 77 studies conducted between 1980 and 1991, among middle and high school students, DeBaz (1994) found a significant gender difference favoring male in overall science achievement. The study by Wangu (2014) which focused on the impact of gender difference on the students' academic performance in Ndumberi Division, Kiambu County on five secondary schools in Kenya, the research findings revealed that by overall performance, male students performed much better as compared to their female 
counterparts. Therefore, it can be observed that based on the gender differences, the girl child is disadvantaged as compared to a boy child.

However, despite the research findings not being consistent with previous studies, the research findings are supported by a strong statistically significant results $(\mathrm{P}=0.012)$ which shows the association between the number of people living with the pupils at home and academic performance. Therefore, the results show a significant association between pupils who lived in homes with 5 to 9 people as compared to those that come from homes with less than 5 or more than 9 people. This finding highlights the fact that in homes with more people, chores are shared and distributed equally reducing the number of chores each individual does. This, therefore, gives more time to female pupils to focus on studying partially explaining why more female pupils proportionally performed better than male pupils.

It is therefore critical for parents or guardian to be cognizant of the type of people they live with at home. Thus, based on the findings, the family size must be able to help with the house chores and also assist the child to study or do schoolwork. It is recommended that the number of people to live at home is observed to be in the range of 5 to 9 .

Further, it is important to note that the family size and support could effectively contribute to pupils' academic performance. This is in line with the findings of Egunsola (2014), which stated that favourable home environment complemented by family support was critical in improving better school performance for the pupils. The finding is also consistent with the theory of Education Productivity (ED) by Walberg et al., (1981) which guided the study. It emphasizes the importance of the home environment as one of the factors affecting academic success of pupils. Based on the theory, it identified three groups of nine factors which include aptitude covering ability, development and motivation: instruction covering amount and quality: environment which covers home and classroom school environment, peers and television (Roberts, 2007).

According to the theory, the home environment should be complemented with other factors to achieve academic performance. The home environment is hardly considered as a vital aspect in determining the academic performance of pupils. However, based on the findings, it can be observed that despite the home being a silent contributor, it plays an important role in the academic performance of pupils. The finding has revealed that family size and support positively affect academic success of a girl child and according to the theory a favourable home environment is a critical factor in enhancing academic performance.

Regarding the relationship between academic performance of pupils coming from electrified and nonelectrified homes, the results showed that there were no statistically significant association in terms of academic performance between pupils coming from electrified and non-electrified homes. However, the results also showed that there were statistically significant association between the number of people at home and having a radio at home with academic performance of pupils coming from the two types of homes. The reason for this observation is not clear but it may be due to that fact that academic performance especially for primary school pupils is influenced by a number of factors and electrification could be one of the factors. The results are therefore in line with the theory of Educational Productivity by Walberg (1981) which guided the study which states that the quality of educational productivity or academic performance of a child is affected by a number of factors.

In view of the above, the findings revealed that there was no significance difference in academic performance between pupils coming from electrified homes and those coming from non-electrified homes. The results are not consistent with previous studies which show that a good home environment (which included availability of electricity) enables pupils to study which aides in improved grades. The study by Kanagawa and Nakata (2008) revealed that access to electricity within a household improves educational outcomes, because pupils have an opportunity to extend studying hours into the night. Similarly, the findings of this study are not in agreement also with the findings of a study by Dave (2013) who found a positive relationship between household electricity consumption and literacy rate in India. Dave (2013) also found that electrification in rural households provided adequate lighting during night-time studying and utilization of television and radio for educational purposes.

On the contrary, the results showing that there is no relationship between pupils coming from electrified homes and academic performance could be supported by findings by Roth (1979). Roth's conclusion resonates with this study's findings, which reveals that the availability of electricity in a home makes it possible for pupils to have access to other facilities such as TVs, video games and radios which may take much of their study time leading to poor academic performance. Therefore, the results are in line with the research findings of Roth (1979) which revealed that there was a negative correlation that existed between the number of television viewing hours per day and academic achievement for selected fourth and seventh grade students in Southwest Louisiana Parish School.

However, it should be noted that the inconsistency in the research findings with previous studies concerning the relationship between pupils coming from electrified homes and academic performance could be attributed to the fact that, the studies were conducted in different contexts. This means that, in the research study, 
environmental factors surrounding a home such as; parents' educational background, socioeconomic status of the families, pupils' interest in school as well as parents' marital status could have played a critical role in influencing the academic performance of pupils. This is also supported by Aisa et.al (2013), who observed that home environmental factors which have been captioned just above, including a couple others such as pupils' interest in school, tend to positively affect the academic performance of pupils.

Therefore, the research findings have revealed that the academic performance of pupils coming from electrified homes is affected by a number of factors and electricity is just one of these factors. The results have revealed that as much as electrification may have an influence on the academic performance of pupils, this effect is mediated by other factors such as family economic status, school environment and individual characteristics of respective pupils which is therefore in line with the fundamentals of the theorem that guided the research. The theorem therefore provides an approach towards understanding how multiple factors such as electricity interacts with other factors to ensure effective learning. Thus, based on the findings, it can be concluded that academic performance is influenced by a number of factors.

It can therefore be noted that, as much as previous studies have shown that electrification may be associated with academic performance, the research finding shows that academic performance is not associated with pupils coming from electrified homes. The research further revealed that academic performance is affected by a number of factors and this finding is in line with the theory of Educational Productivity by Walberg (1981) which guided the study.

Regarding the factors affecting academic performance of pupils coming from electrified rural homes, the results show that there is no statistically significant association between some of the home environmental based factors such as parents' socioeconomic condition, professional qualification and occupation. This meant that the socioeconomic factors such as parents' education, income, wealth, and place of residence did not affect the academic performance of the pupils coming from electrified home. The non-association between socioeconomic factors was also observed by Blevins (2009) and Parri (2006) who concluded in the studies that the identification and measuring of factors effecting academic performance of learners was not a simple issue but a complex process which increased with the changing values of quality which was attributed to the different stakeholders' viewpoint. Further, Berhanu et.al (2011) concluded that to identify all the factors affecting students' quality of academic performance in a single attempt was a complex and challenging task.

Therefore, as earlier indicated, the research findings revealed that academic performance is affected by a number of factors. The process of identifying these factors is influenced by a number of other factors. The finding thus confirms to the theory that supported the study. The theory of Educational Productivity by Walberg et al., (1981) identified nine factors and it is argued that the combination of these variables could maximize productivity of education. We may conclude that these factors are dependent on each other as they complement one another to influence effective learning which will trigger the phenomenon of academic success Nuhu et.al (2014). Optimization of the factors as identified by the theory could therefore make the most of education productivity which in turn influences academic performance (Marzano, 2003).

However, contrary to the research findings, a number of studies have shown that there is a direct relationship between various factors linked to social-economic status of the family. This relationship is also supported by the study done by Graetz (1995) which revealed that student educational success is heavily contingent on the wealth of the student's parents or guardians. Ali et.al (2013) found that the parent's socioeconomic condition, which included parents' academic and professional qualification including occupational affiliation, was associated with academic gain of pupils. Conversely, it is imperative to note that the low socioeconomic status has a negative effect on the academic performance of pupils because their basic needs remain unfulfilled hence, they do not perform better academically (Adams, 1996).

Regarding the contribution of the home environmental factors such as guardians' level of education and employment status, to mention a few, towards the association between academic performance and pupils coming from electrified homes, multivariate logistic regression (model 5) shows that the value of OR increased from 0.882 to 0.946 when factors related to home environmental factors which are proportional to the socioeconomic status of the pupil were included in the model. However, the increase in OR is mainly attributed to two factors namely: the number of people living with the respondents and to a certain extent, pupils living with guardians possessing university level of education. The two factors have been identified as the main contributor to the increase in the OR owing to the fact that the value of OR for the rest of the factors, were approximately closer to 1 and this meant that their contribution was negligible.

Therefore, the number of people living with the respondents is statistically significantly associated with academic performance with $\mathrm{OR}=4.071$ while pupils with guardians possessing University level of education showed $\mathrm{OR}=2.221$. however, it is important to note that the result was not statistically significant.

Thus, based on the positive increase and values of ORs, the two factors played critical roles in enhancing academic performance of pupils coming from electrified homes. The results have thus revealed that, apart from the statistically significant result of the number of people staying with the pupil, to a certain extent, the 
guardian's level of education contributes to high academic performance of learners coming from electrified homes. This stems from the fact that parents' level of education may provide an opportunity to have access to resources such as income and that parents were more likely to be concerned with the child's school activities, allowing for better parental involvement in their education. In addition, parental level of education influences parental knowledge, beliefs, values and goals about child rearing. When all these are put into account, the children's attitude towards education is positively enhanced.

Therefore, academic background of the concerned parent is such a motivating factor for a child and influences a child's future. According to Davis-Kean (2005), a parents' educational level is an important predictor of children's education and behavioral outcomes. Previous studies have also revealed that parental education is indeed a crucial and significant unique predictor of a child's achievement. According to Young and Smith (1997), children of well-educated parents, on average perform better on academic assessment tests than children of high school-educated parents. The study by Young and Smith (1997), further revealed that educational attainment of the parents is independent of the income because the level of education may influence the value that parents put on education, which could, in turn, influence their children's goals.

On the other end, failed students belong to those whose parents or guardians have lower levels of education. In 2017, a study was conducted in Mombasa-Kenya, the findings revealed that illiterate parents were unable to assist their children with homework and that parents who do not go beyond elementary or secondary schools are unable to give proper assistance to their children in their educational problems. Some researchers have, however, not agreed with this. They argue that children's academic achievements in most cases do not necessarily depend on parents' level of education. For example, Hawkes (1995) in his research study of parent's educational attainments concluded that there was no relationship between students' academic achievements and the former. Therefore, it is not always the case that pupils living with parents that have lower levels of education will be associated with negative learning environment as some pupils may rise above the odds to succeed.

Based on the results, it is observed that the number of people staying with a pupil and to a certain extent, the guardian's level of education contributes to high academic performance of learners coming from electrified homes.

\section{Conclusion}

The study concluded that there was no significant difference between male and female pupils even though proportionally, more female pupils performed better than their male counterparts. The results were supported by a statistically significant level of association between the number of people living with the pupil at home and academic performance. The findings highlighted the fact that in homes with more people, chores are shared and distributed equally reducing the number of chores each individual does. This, therefore, gives more time for female pupils to focus on studying, partially explaining why more female pupils comparably performed better than male pupils

The study also observed that there is a statistically significant association between the radio and academic performance of pupils coming from the two types of homes. It was also observed that, academic success is influenced by three factors which are: the number of people living with the respondents and having a radio for pupils coming from the two types of homes while to a certain extent guardians' level of education for pupils only coming from electrified homes. This relationship conforms to the theory that guided the study which states that, the quality of educational productivity or academic performance of a child is affected by a number of factors.

\section{Recommendation}

Based on the conclusion, the following recommendations were made:

Parents and guardians should be cognizant of the type of family members they live with at home, and based on the findings, these members should be able to help with the house chores as well as assist the girl child to study or do schoolwork. This will, therefore, give more time to a girl child to focus on studying which may positively influence her academic performance.

Secondly, it is imperative that more homes be electrified so that pupils are prompted and encouraged to listen to educational programs on the radio and television. In addition to this, parents or guardians from electrified homes should aspire to acquire higher qualifications such as a University degree as this will act as a vessel for pupils to want to excel academically.

\section{References}

Adams, A. (1996). Even basic needs of young are not met. Retrieved from http://tc.education. pitt.edu/library/Self Esteem

Ali et.al (2013). Factors contributing to the students' academic performance: a case study of Islamic University sub-campus. American Journal of Educational Research, Vol. 1, No. 8, 283-289

Amin, E (2005), Social Science Research, Makerere University Printery, Kampala, Uganda 
Blevins, B. M. (2009). Effects of socioeconomic status on academic performance in Missouri public schools. Retrieved from http://gradworks.umi.com/3372318.pdf

Considine, G. \& Zappala, G. (2002). Influence of social and economic disadvantage in the academic performance of school students in Australia. Journal of Sociology, 38, 129-148.

Crosnoe, R., Johnson, M. K., \& Elder, G. H. (2004). School size and the interpersonal side of education: An examination of race/ethnicity and organizational context. Social Science Quarterly, 85(5), 1259-1274.

Dave, M.,2013: When the lights go on: household electrification and educational outcomes in rural India, Georgetown University, Washington, DC

Ekanem, TF (2004). The School as a Substitute Home in Q.I. Obinaju (Ed), Theory and Practice in Early Childhood Education. Calabar: Bon Ltd.

Egunsola, A. O. E. (2014). Influence of home environment on academic performance of secondary school students in Agricultural Science in Adamawa State Nigeria. IOSR Journal of Research \& Method in Education (IOSR-JRME), Volume 4, pp 46-53

Graetz, B. (1995), Socio-economic status in education research and policy in John Ainley et al., Socio-economic Status and School Education DEET/ACER Canberra.

John, W. Creswell (2014), Research Design. $4^{\text {th }}$ Edition 2014: Singapore: SAGE Publication

Kanagawa, M. and Nakata, T. (2008). Assessment of access to electricity and the socio-economic impacts in rural areas of developing countries. Energy Policy. 36(6),2016-2029. Retrieved fromScienceDirect.com https://www.sciencedirect.com/science/article/pii/,6June 2018.

Mitchell, M. L. \& Jolley, J. M. (2013). Research design explained. ( $8^{\text {th }}$ ed.). Belmont, CA: Wadsworth/Cengage.

Parri, J. (2006). Quality in higher education. Vadyba/management, 2(11),107-111

Simon, M. K. and Goes. J (2011). Correlational Research. Dissertation and Scholarly Research: Recipes for Success. Seattle, WA: Dissertation Success LLC, pp 1-2.

\section{Autobiography}

Patrick Mubanga is an Electrical Engineer working for Rural Electrification Authority. He holds a master's degree in Sustainable Energy Engineering from KTH Sweden and is currently studying for a PhD programme at University of Zambia. He has published 3 journals on Energy with Engineering Institute of Zambia. His focus of interest is in the field of energy, concentrating on sustainably supplying power using renewable energy to remote communities that are located far from the National Grid.

Dr. Daniel Ndhlovu is a lecturer at the University of Zambia working in the Department of Educational, Psychology, Sociology and Special Education. He has over 29 years of teaching and administrative experience. $\mathrm{He}$ is a researcher and has written and published more than 30 articles in International Journals peer reviewed journals. He has also co-authored four books and single authored one book which is presently being used in schools, colleagues and Universities. So far, he has supervised and examined 100 masters and PhD students. His focus of interest includes Special Education, Guidance and Counselling, Teacher Education and Early Childhood Education. 
Appendix 1: Results

Table 1: Background information: Distribution of respondents by their characteristics

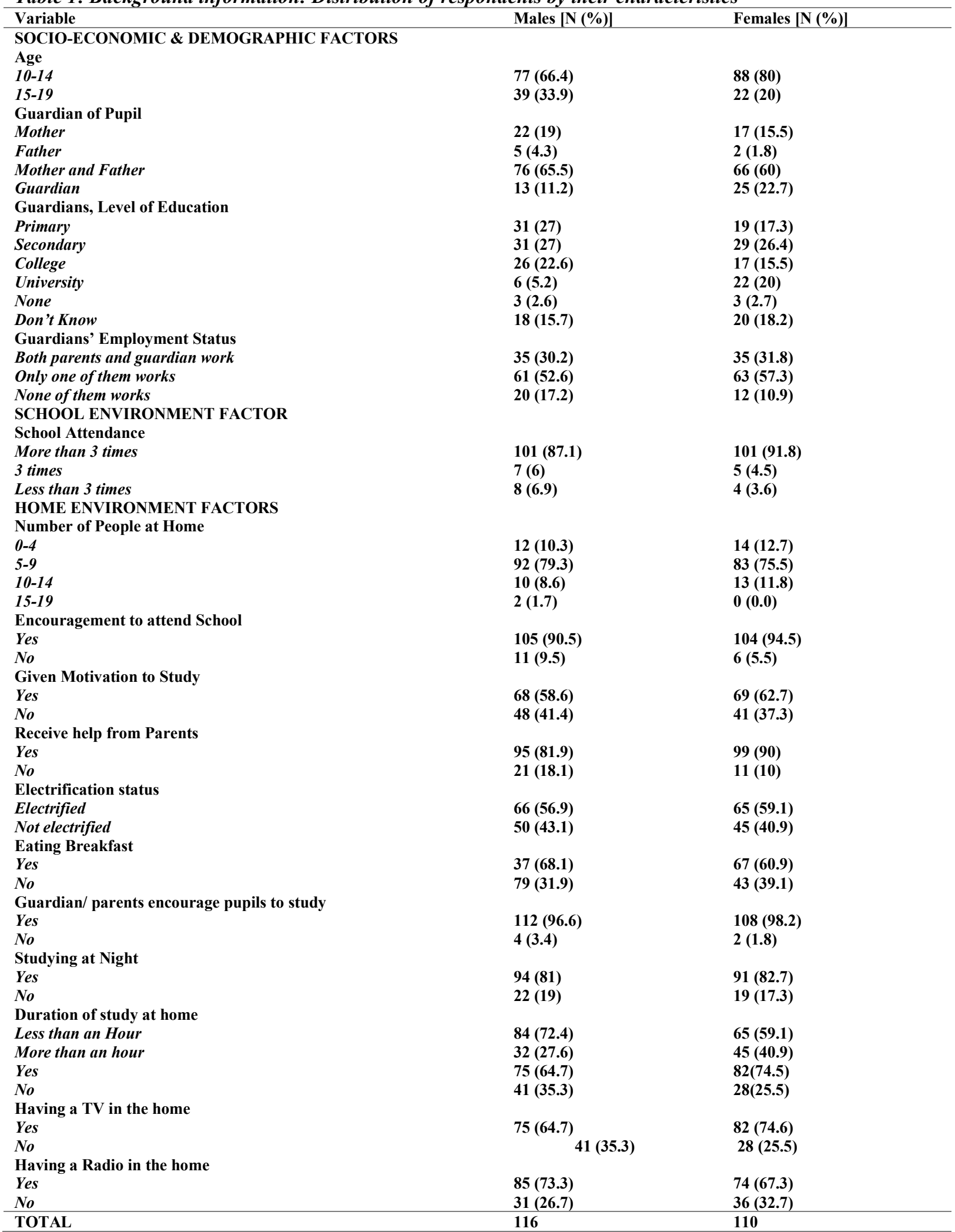


Table 2: Bivariate analysis of academic performance of pupils coming from electrified and non-electrified homes

\begin{tabular}{|c|c|c|}
\hline \multirow{2}{*}{\multicolumn{3}{|c|}{$\begin{array}{lr}\text { Variable } & \text { N (\%) } \\
\text { SOCIO-ECONOMIC \& DEMOGRAPHIC CHARACTERISTICS }\end{array}$}} \\
\hline & & \\
\hline \multicolumn{3}{|c|}{ Sex } \\
\hline Male & $45(38.79)$ & 0.119 \\
\hline Female & $54(49.09)$ & \\
\hline \multicolumn{3}{|l|}{ Age } \\
\hline 10-14 & $77(46.67)$ & 0.154 \\
\hline \multirow{2}{*}{\multicolumn{3}{|c|}{ Guardian of Pupil }} \\
\hline & & \\
\hline Mother & $16(41.03)$ & 0.789 \\
\hline Father & $2(28.57)$ & \\
\hline Mother and Father & $65(45.77)$ & \\
\hline Guardian & $16(42.11)$ & \\
\hline \multicolumn{3}{|l|}{ Guardians, Level of Education } \\
\hline Primary & $20(40.00)$ & 0.114 \\
\hline Secondary & $30(50.00)$ & \\
\hline College & $15(34.88)$ & \\
\hline University & $18(64.29)$ & \\
\hline None & $1(16.67)$ & \\
\hline Don't Know & $15(39.47)$ & \\
\hline \multicolumn{3}{|l|}{ Guardians' Employment Status } \\
\hline Both parents and guardian work & $33(47.14)$ & \\
\hline Only one of them works & $53(42.74)$ & 0.777 \\
\hline None of them works & $13(40.63)$ & \\
\hline \multicolumn{3}{|c|}{ SCHOOL ENVIRONMENT FACTORS } \\
\hline \multicolumn{3}{|c|}{ School Attendance } \\
\hline More than 3 times & $87(43.07)$ & \\
\hline 3 times & $4(33.33)$ & 0.209 \\
\hline Less than 3 times & $8(66.67)$ & \\
\hline \multicolumn{3}{|c|}{ HOME ENVIRONMENT SUPPORT } \\
\hline \multicolumn{3}{|c|}{ Encouragement to Attend School } \\
\hline Yes & $93(44.50)$ & \\
\hline No & $6(35.29)$ & 0.462 \\
\hline \multicolumn{3}{|l|}{ Given Motivation to Study } \\
\hline Yes & $57(41.61)$ & \\
\hline No & $42(47.19)$ & 0.408 \\
\hline \multicolumn{3}{|l|}{ Receive Help from Parents } \\
\hline \multicolumn{3}{|l|}{ Yes } \\
\hline No & $86(44.33)$ & 0.696 \\
\hline & $13(40.63)$ & \\
\hline Number of People at Home & & \\
\hline $0-4$ & $5(19.23)$ & \\
\hline $5-9$ & $84(48.00)$ & $0.012 *$ \\
\hline 10-19 & $10(40.00)$ & \\
\hline Electrification Status & & \\
\hline Electrified & $57(43.51)$ & 0.917 \\
\hline Not electrified & $42(44.21)$ & \\
\hline Eating Breakfast & & \\
\hline Yes & $59(40.41)$ & 0.165 \\
\hline No & $40(50.00)$ & \\
\hline Guardian/ parents encourage pt & & \\
\hline Yes & $96(43.64)$ & 0.757 \\
\hline No & $3(50.00)$ & \\
\hline Studying at Night & & \\
\hline Yes & $84(45.41)$ & \\
\hline & & 0.303 \\
\hline No & $15(36.59)$ & \\
\hline Duration of study at home & & \\
\hline Less than an Hour & $70(46.98)$ & 0.181 \\
\hline More than an hour & $29(37.66)$ & \\
\hline Whether electricity at home enc & & \\
\hline Yes & $68(43.31)$ & 0.822 \\
\hline No & $31(44.93)$ & \\
\hline Having a radio in the home & & \\
\hline Yes & 39.62 & $0.051 * *$ \\
\hline No & 53.73 & \\
\hline Having a TV in the home & & \\
\hline Yes & 43.31 & \\
\hline No & 44.93 & 0.822 \\
\hline
\end{tabular}


Table 3: Multivariate Logistic Regression analysis of academic performance of pupils coming from electrified homes

\begin{tabular}{|c|c|c|c|c|c|}
\hline Variable & Model1 & Model2 & Model3 & Model4 & Model5 \\
\hline \multicolumn{6}{|l|}{ ELECTRIFICATION STATUS } \\
\hline Not electrified & 1.00 & 1.00 & 1.00 & 1.00 & 1.00 \\
\hline Electrified & 0.972 & 0.960 & 0.911 & 0.882 & 0.946 \\
\hline \multicolumn{6}{|l|}{ SEX } \\
\hline Male & & 1.00 & 1.00 & 1.00 & 1.00 \\
\hline Female & & 1.451 & 1.541 & 1.582 & 1.642 \\
\hline \multicolumn{6}{|l|}{ AGE } \\
\hline $10-14$ & & 1.00 & 1.00 & 1.00 & 1.00 \\
\hline $15-19$ & & 0.685 & 0.692 & 0.647 & $0.510^{*}$ \\
\hline \multicolumn{6}{|c|}{ DURATION OF STUDY AT HOME } \\
\hline Less than an Hour & & & 1.00 & 1.00 & 1.00 \\
\hline More than an hour & & & 0.648 & 0.665 & 0.590 \\
\hline \multicolumn{6}{|l|}{ STUDYING AT NIGHT } \\
\hline No & & & 1.00 & 1.00 & 1.00 \\
\hline Yes & & & 1.573 & 1.555 & 1.996 \\
\hline \multicolumn{6}{|l|}{ SCHOOL ATTENDANCE } \\
\hline More than 3 times & & & & 1.00 & 1.00 \\
\hline 3 times & & & & $0.228^{*}$ & $0.170^{*}$ \\
\hline Less than 3 times & & & & $0.324 *$ & $0.275^{*}$ \\
\hline \multicolumn{6}{|l|}{ GUARDIAN OF PUPIL } \\
\hline Mother & & & & & 1.00 \\
\hline Father & & & & & 0.866 \\
\hline Mother and Father & & & & & 1.109 \\
\hline \multirow{2}{*}{\multicolumn{6}{|c|}{ GUARDIANS, LEVEL OF EDUCATION }} \\
\hline & & & & & \\
\hline Primary & & & & & 1.00 \\
\hline Secondary & & & & & 1.355 \\
\hline College & & & & & 0.712 \\
\hline University & & & & & 2.221 \\
\hline \multicolumn{6}{|c|}{ GUARDIANS' EMPLOYMENT STATUS } \\
\hline Both parents \& guardian work & & & & & 1.00 \\
\hline Only one of them works & & & & & 0.975 \\
\hline None works & & & & & 0.859 \\
\hline \multicolumn{6}{|c|}{ SEEKING ACADEMIC ASSISTANCE FROM GUARDIAN } \\
\hline No & & & & & 1.00 \\
\hline Yes & & & & & 1.058 \\
\hline \multicolumn{6}{|l|}{ EATING BREAKFAST } \\
\hline No & & & & & 1.00 \\
\hline Yes & & & & & 0.721 \\
\hline \multicolumn{6}{|c|}{ NUMBER OF PEOPLE IN THE HOME } \\
\hline $1-4$ & & & & & 1.00 \\
\hline 5-9 & & & & & $4.071^{* *}$ \\
\hline 10-14 & & & & & 3.439 \\
\hline \multicolumn{6}{|l|}{ Having a radio in the home } \\
\hline No & & & & & 1.00 \\
\hline Yes & & & & & 0.635 \\
\hline \multicolumn{6}{|l|}{ Having a TV in the home } \\
\hline Yes & & & & & 1.00 \\
\hline No & & & & & 1.058 \\
\hline${ }^{*} \mathbf{p}<0.10,{ }^{* *} \mathbf{p}<0.05, * * * p<0.01$ & $\mathrm{~F}=0.01, \mathrm{P}>0.05$ & $\begin{array}{l}F=3.93 \\
P>0.05\end{array}$ & $\begin{array}{l}F=7.55 \\
P>0.05\end{array}$ & $\begin{array}{l}F=11.19, \\
P<0.05\end{array}$ & $\begin{array}{l}F=31.59 \\
P>0.05\end{array}$ \\
\hline
\end{tabular}

